\title{
A reappraisal of the evidence that rheumatoid arthritis and several other idiopathic diseases are slow bacterial infections
}

\author{
G A W Rook, P M Lydyard, J L Stanford
}

The idea that several 'idiopathic' or 'autoimmune' diseases are in fact caused by bacteria, probably related to the mycobacteria, which grow very slowly in the host, has been reported for some time. The diseases concerned are rheumatoid arthritis (RA), sarcoidosis, the inflammatory bowel diseases (Crohn's disease and ulcerative colitis), psoriasis, Takayasu's arteritis, and conceivably, 'giant cell arteritides', such as polymyalgia rheumatica. New data have increased the appeal of this hypothesis, and technical developments now make it accessible to investigation. The first section of this paper outlines the features of accepted slow bacterial infections, and points out the parallels with $\mathrm{RA}$, inflammatory bowel disease, and sarcoidosis, including the presence of autoantibodies, agalactosyl IgG, and arthritis. The rest of the paper analyses these similarities in greater detail and reviews the evidence for two other crucial points: firstly, that there is altered responsiveness to mycobacteria in RA (and sarcoidosis); secondly, that mycobacteria can exist in forms which are difficult to detect by conventional histological techniques, and difficult to culture, but which are associated with the 'autoimmune' diseases considered here.

\section{Slow bacterial infections}

Several bacterial genera, notably the spirochaetes (Lyme disease and syphilis) and the mycobacteria, can cause very slowly evolving infections with characteristically varied presentation and complex evolution. These features are due in part to unexplained tropisms which localise the infection in certain sites, and in part to the 'spectrum' of immune responses which they can evoke. This can be dominated by $\mathrm{T}$ cell activity, as in tuberculoid leprosy, or by antibody formation, as in lepromatous leprosy. Moreover, the nature of the response can change with time, resulting in the extraordinarily complex sequences of clinical manifestations classically seen in untreated leprosy or syphilis.

When the antibody response is dominant these infections can be accompanied by a reactive arthritis, by autoantibodies including rheumatoid factor, and by strikingly raised levels of agalactosyl immunoglobulin $G$ $(\mathrm{Gal}(0))$. This pattern of disease mimics features of the 'idiopathic' or 'autoimmune' disorders, particularly RA.
When the $\mathrm{T}$ cell mediated response is prominent in a slow bacterial infection, autoantibody formation can be less striking, and the disease process generates $T$ cell dependent granulomata with variable degrees of central necrosis. This necrosis is seen in tuberculosis and in the gumma of tertiary syphilis, and overlap with the histological appearance of rheumatoid skin nodules has often been noted. However, necrosis is not a feature of infections due to Mycobacterium intracellulare and $M$ malmoense in the cervical lymph nodes of children, and the histology of these infections more closely resembles that of sarcoidosis.

Slow bacterial infections have a predilection for the lungs (tuberculosis), skin (leprosy, $M$ ulcerans, $M$ marinum), and gut. The ability of mycobacteria to infect the gut deserves further emphasis. Some variants of $M$ avium (mycobactin dependent), including the organism known as $M$ paratuberculosis, cause a chronic granulomatous intestinal infection in cattle, goats, and deer, and recently a similar disease has been described in monkeys. ${ }^{1}$ With loss of CD4 T cells in HIV infected persons, a limited number of serotypes of mycobactin independent $M$ avium can cause similar appearances in the human intestine. ${ }^{2}$ Such infections with conventional mycobacteria are in many ways similar to the inflammatory bowel disease spectrum. ${ }^{3}$ In fact sarcoidosis, Crohn's disease, and RA tend, like the established slow bacterial infections, to affect the lungs, skin, and gut. Thus although Crohn's disease is an inflammatory bowel disease, the lung lavages of these patients are grossly abnormal, ${ }^{4}$ and lung damage is a serious complication in some cases of RA. ${ }^{5}$ Similarly, there is evidence for gut abnormalities in sarcoidosis ${ }^{6}$ and RA, ${ }^{7}$ and arthritis can occur in all of these conditions. ${ }^{8} 9$ It should be stressed that this pattern of disease is quite unlike that seen in the organ specific disorders of proved autoimmune aetiology (such as the endocrinopathies or Myasthenia gravis).

Whipple's disease is a rare slow bacterial infection which illustrates particularly well the conceptual and diagnostic dilemma. This disease is associated with the presence, within macrophages, of non-cultivable organisms, demonstrable by electron microscopy and sometimes by the periodic acid-Schiff technique. The commonest symptoms at diagnosis are weight loss, diarrhoea, arthralgias, abdominal pain, and skin changes. The 
infection progresses so slowly that symptoms can be present for 10 years before a diagnosis is made. The presentation is very variable, and the infection can mimic Crohn's disease or sarcoidosis, ${ }^{10}$ or even present as a longstanding seronegative polyarthritis. ${ }^{11}$ It has recently been reported that the sequence of the gene encoding the $16 \mathrm{~S}$ ribosomal RNA of the organisms from a single case of Whipple's disease most closely resembled that found in Rhodococcus, Arthrobacter, and Streptomyces, and slightly less closely resembled the sequence found in mycobacteria. ${ }^{12}$

\section{Reactive arthritis}

As arthritis can occur in RA, Crohn's disease, ${ }^{9}$ sarcoidosis, ${ }^{8}$ and psoriasis, it is particularly important to note that the established slow bacterial infections can also be accompanied by this symptom. This is sometimes owing to direct infection of the joint. Most slow bacterial infections, however, can also be accompanied by a 'reactive arthritis', similar in some ways to that seen in patients transiently and superficially infected in the gut or genitourinary tract by Yersinia, Chlamydia, Shigella, Salmonella, etc. This kind of arthritis can be the presenting symptom in Whipple's disease, ${ }^{11}$ and it can be seen in a minority of patients with leprosy, ${ }^{13} 14$ tuberculosis, ${ }^{15-19} M$ avium infection, ${ }^{20}$ or after BCG immunotherapy for cancer. ${ }^{2122}$ It is characteristic of reactive arthritis that the genome of the causative organism is not present within the joints but that the joint contains both antigens derived from the organism, and $\mathrm{T}$ cells responding to those antigens. ${ }^{23-26} \mathrm{~T}$ cells responding to antigens that are confined to the mycobacteria, and to a very closely related genus, are also found in rheumatoid joints (see below).

\section{Epidemiology}

The epidemiology of sarcoidosis and Crohn's disease points to an environmental factor, ${ }^{27-29}$ likely to be an infection, because there is well documented clustering in space and time, and geographical variation independent of race. The epidemiology of RA is less obvious, though studies of fossil evidence suggest that it is a recent disease, which has behaved like an epidemic in the West, but has now reached a peak and may even be declining. Meanwhile, there is evidence that a similar epidemic has begun in Africa, where incidence in peoples of similar genetic background depends on whether they they live in urban or rural environments. Similarly, twin concordance studies show that RA is about $30 \%$ genetic, so an environmental factor is involved, and in a recent review Silman concludes that this factor is most likely to be an infection. ${ }^{30}$

\section{Serological changes in patients with Crohn's disease and RA, and in their spouses}

The autoantibodies seen in RA clearly do not constitute evidence that the disease is primarily due to autoimmunity. These autoantibodies, including rheumatoid factor, are essentially similar to those seen in the accepted slow bacterial infections, ${ }^{31}$ particularly when the antibody response is prominent, as in lepromatous leprosy. It is possible that they contribute to immunopathology, but it is no more logical to regard them as the primary problem in RA than it would be in the mycobacterial diseases, unless the greater titres or higher affinities, or both, characteristic of RA cause them to become pathogenic. Interestingly, some of the serological changes seen in RA and Crohn's disease provide rather strong evidence for an infectious component. Lymphocytotoxic activity, detected in the serum of patients with Crohn's disease, was also present in the serum of their spouses. ${ }^{32}$ In addition spouses of patients with RA, like the patients themselves, have raised levels of agalactosyl IgG $(\mathrm{Gal}(0)),{ }^{33}$ (discussed further below), the PR4 idiotype, ${ }^{34}$ and an apparent change in the activity of a DNA repair enzyme. ${ }^{35}$ These observations are all compatible with a transmissible agent. Indeed they are difficult to explain in any other way.

\section{HLA, sex differences, and spouses}

The findings reviewed in the previous section imply at first sight that the spouses of patients with RA ought to develop the disease. In fact there is no reason why this should happen, and we must distinguish between transmission of an infection and development of the disease. Disease is merely one possible outcome of the host/microbe relation. In fact there are numerous reports of Crohn's disease developing in spouses, and even sarcoidosis has appeared simultaneously in spouses. ${ }^{36}$ In RA this may not occur because of the HLA associations and sex differences. The spouse tends to be male and is not necessarily genetically susceptible (for instance, DR4 positive). Thus even if the agent is transmitted to the spouse it need not cause disease Transmission of mycobacterial disease within families can parallel this situation for similar reasons. HLA associations also occur in leprosy (though the relevant haplotypes are different $),{ }^{37}$ and sex differences $(F>M)$ in $R A$ are mirrored by the reverse sex difference in tuberculosis, which is markedly commoner in men.

\section{$T$ cell mediated autoimmunity in RA, inflammatory bowel diseases, and sarcoidosis}

If neither the arthritis nor the autoantibodies necessarily point to an autoimmune aetiology, can we deduce anything from the $T$ cell responses in these diseases? There have been extensive searches for autoreactive $T$ cells. Occasional $\mathrm{T}$ cell clones responsive to type II collagen can be detected in some rheumatoid synovial fluid $T$ cell populations. ${ }^{38}$ Such reactivity is not present in all patients, however, and can be found in the peripheral blood of normal donors. ${ }^{39}$ Moreover, there is now some 
doubt about the validity of at least some work on $T$ cell reactivity to collagen because the pepsin used to prepare it is a potent $\mathrm{T}$ cell stimulus and has been shown to account for much of the apparent reactivity in both murine and human studies. ${ }^{40}$

The possibility that there is autoreactivity to heat shock proteins (hsps) is more difficult to analyse. There is concrete proof that sequences derived from the mycobacterial 65 kilodalton hsp are relevant to most, perhaps all, the rodent models of arthritis, ${ }^{41-44}$ so it was logical to seek evidence for responses to this protein in human disease. The data on this point are conflicting, as discussed later, but most authors agree that there are at least some $\mathrm{T}$ cells responding to mycobacterial hsp65 in rheumatoid joints. Do any of these $T$ cells also recognise the human homologue, which is the 60 kilodalton mitochondrial hsp? There are reports that some $\mathrm{T}$ cells from reactive arthritis and from juvenile chronic arthritis do indeed have this property, though the frequency of such cells is not clear. ${ }^{45}$ When the epitopes recognised by other clones responding to the mycobacterial hsp65 were studied they turned out to be sequences with only limited homology to the human protein. ${ }^{46}$ These clones will respond to the corresponding human sequence, but only when this is present at high concentrations. At first sight this seems to imply that this cross reactivity is irrelevant, but recent findings in a quite different model suggest that this conclusion may be premature. A study of the sequence from myelin basic protein, which is involved in the pathogenesis of experimental autoallergic encephalitis in mice, has shown that the peptide causing disease has a remarkably low affinity for the major histocompatibility complex (MHC). Changes to the sequence which increase the binding to the MHC while conserving the moieties involved in the interaction with $T$ cells allow the same $T$ cells to recognise a much lower concentration of the peptide. However, such a peptide, instead of inducing the disease more readily, actually blocks disease induction. ${ }^{47}$ Presumably this peptide leads to suppression, inactivation, or elimination of the $\mathrm{T}$ cells which recognise it, whereas the response to the original peptide, with its low affinity binding to the MHC, escapes the relevant regulatory mechanism. The implications for the hsp60 story are clear. We cannot dismiss it yet.

Another aspect of the hsp60 story is also suggestive. Several groups have noted that murine or human $\mathrm{T}$ cell clones or lines responsive to the human or bacterial hsp may recognise stressed autologous cells and can indeed kill them. ${ }^{48-51}$ This implies that the mitochondrial hsp60 can be processed and that cross reactive peptides can be presented. This may well be a physiological mechanism with some as yet obscure regulatory role. At present we are unaware of any studies aimed at finding out whether hsp65 reactive $T$ cells from patients with tuberculosis or leprosy are also able to recognise such stressed cells in the absence of external antigen. If, as we predict, they can do so, it will be difficult to claim that this mechanism is specific for RA, or a primary event in its pathogenesis.

The complexity of the hsp60 story has been further increased by a series of publications claiming that cells can express not just MHC bound peptides derived from the hsp 60 but even macromolecular forms detectable with a variety of polyclonal and monoclonal antibodies to the mycobacterial ${ }^{52}$ or mammalian homologues. ${ }^{53}$ Whereas this work certainly suggests that something cross reactive with this family of hsps can appear on mammalian cell membranes, there is no evidence that this is in fact the hsp60. Indeed the monoclonal antibody ML30 used in some of these studies binds to numerous mammalian constituents. Nevertheless, a cross reactive molecule may be relevant, and its identification is awaited with interest.

Thus although there are several 'loose ends', particularly in relation to the role of hsps as autoantigens, there is no evidence that there are autoimmune manifestations in RA which are not routinely seen in slow bacterial infections, with perhaps the exception of higher affinity self reactive antibodies.

\section{Second signals and autoreactive $T$ cells}

An unresolved theoretical issue is relevant here. It is not clear that autoreactive $T$ cells can function in the absence of a 'second signal'. This second signal may be provided by those microbial components which are recognised independently of the receptors on $\mathrm{T}$ cells and B cells. These components include glycolipids, polyanions, peptidoglycans, formyl peptides, mannans, glucans, etc, and constitute the 'adjuvant' components without which most animal models of autoreactivity cannot be elicited. This requirement for a second signal ensures that potentially autoreactive responses are activated only when an infectious agent is present, and may even allow the immune response to perform some elementary 'taxonomy', and so activate the mechanism appropriate for the organism in question. ${ }^{56}$ Does sustained $\mathrm{T}$ cell autoreactivity occur without the continuing presence of microbial components? Do rodent models such as adjuvant arthritis tend to be self limiting (unlike the human diseases they are intended to illustrate) because the microbial components needed to provide the 'second signal' are present only as a single injection at the start of the experiment?

\section{Reactivity to mycobacterial antigen in the idiopathic diseases}

The points discussed in the two previous sections lead us to suggest that the hsp story, even if it turns out to be true, is merely another pointer towards a bacterial, or perhaps mycobacterial aetiology. Furthermore, there is much additional evidence for altered responsiveness to mycobacteria in RA. Patients with RA have raised levels of antibody to crude mycobacterial antigen preparations. ${ }^{57}{ }^{58}$ When 
Skin test responses to a sonicate preparation of $M$ tuberculosis in normal subjects, and in patients with rheumatoid arthritis or tuberculosis. The (number of subjects) percentage positive is shown

\begin{tabular}{lllll}
\hline & $D R 4$ & Non-DR4 & DR7 & Non-DR7 \\
\hline Controls & $(20) 95$ & $(59) 92$ & $(29) 83$ & (50) 98 \\
Tuberculosis & $(18) 78$ & $(93) 88$ & $(34) 88$ & $(77) 92$ \\
Rheumatoid arthritis & $(14) 79^{\star}$ & $(32) 44$ & (13) $23^{\star}$ & (33) 67 \\
\hline
\end{tabular}

${ }^{\star} \mathrm{p}<0.001$ when reaction sizes are compared with those of subjects without the indicated haplotype using the Mann-Whitney U test. (Data adapted from ref 59.)

patients with RA were skin tested with such preparations, derived from four different mycobacterial species, they gave an abnormal pattern of response characteristic of infected subjects. Moreover, the skin test responses were larger ${ }^{59}$ and more frequently positive (table) in DR4 positive than in DR4 negative rheumatoid patients, and smaller ${ }^{59}$ and less frequently positive (table) in DR7 positive than in DR7 negative rheumatoid patients. ${ }^{59}$ These correlations with HLA were not seen in normal controls or in patients with tuberculosis. However, DR4 was associated with larger responses to tuberculin $(p=0.0005)$ in patients with leprosy. ${ }^{60}$ Although this correlation is not seen in skin test studies of normal subjects, in vitro studies suggest that there is a component of $M$ tuberculosis to which $\mathrm{T}$ cells from DR4 positive subjects, even when from normal donors, tend to give larger proliferative responses. ${ }^{61}$

Patients with RA also have increased antibody to the mycobacterial 65 kilodalton $\mathrm{hsp},{ }^{586263}$ and there is also a report that patients with psoriasis have increased antibody to this and other mycobacterial components. ${ }^{64}$ Some authors have also found that rheumatoid synovial fluid $T$ cell populations show increased proliferative responses to this antigen. ${ }^{65}{ }^{66}$ The most convincing data come from juvenile patients. ${ }^{45}$ Nevertheless this matter is controversial for two reasons. Firstly, the recombinant hsp65 preparations studied were contaminated with $E$ coli products. Secondly, most authors failed to perform limiting dilution analysis to determine the frequency of responding $T$ cells, and in fact the responses of synovial cells may be no higher than normal, particularly when the superiority of the antigen-presenting function of synovial fluid cells is taken into account. ${ }^{67}$ The hsp is a special case, however, because of its homology with the human hsp60, and - was considered above in relation to autoimmunity.

Other mycobacterial antigens are also recognised by $T$ cells or antibodies from patients in this disease group. By immunoblotting, juvenile patients with RA were shown to have antibody to the 18.6 and 30 kilodalton antigens $^{68}$ (though there were no disease controls from an irrelevant inflammatory disease). The 30 kilodalton fibronectin binding antigens are of particular interest because western blot analysis of extracts of Gordonella, Corynebacteria, Tsukamurella, Nocardia, and Rhodococcus (supplied by Professor M Goodfellow), using polyclonal antisera to the 30 kilodalton antigens, suggests that they are absent from these related genera, with the exception of some weakly cross reactive, fibronectin binding components of higher molecular weight in the nocardiae (McCulloch, Rook, Abou-Zeid, et al, unpublished observation). Patients with sarcoidosis also have significantly raised antibody to the 30 kilodalton proteins (Fidler, Abou-Zeid, O'Connor, et al, unpublished data), and T lymphocytes from the joints of patients with RA respond better to them than they do to the 65 kilodalton hsp ${ }^{68}{ }^{69}$; another study may be interpreted similarly. ${ }^{70}$ Our own preliminary data support this finding (Smith, Lydyard, Abou-Zeid, unpublished data).

Takayasu's arteritis is of special interest because this granulomatous giant cell arteritis is often accompanied by arthritis and mimics a range of 'idiopathic' or 'autoimmune' diseases. ${ }^{71}$ However, it can now be definitively associated with $M$ tuberculosis because the patients have striking levels of antibody to a 38 kilodalton protein which is unique to $M$ tuberculosis, exaggerated tuberculin responses, and very high \%Gal(0) (Hernandez-Pando, Reyes, Espitia, et al, unpublished data). Agalactosyl IgG is proving to be an important marker and is discussed in the next section.

\section{Agalactosyl IgG: a further link between infection and RA?}

This glycoform of IgG lacks the terminal galactose from the conserved biantennary oligosaccharides situated on the $\mathrm{CH} 2$ domain (fig 1 ). The $\% \mathrm{Gal}(0)$ correlates closely with disease activity in RA, and if assayed early in disease, with prognosis. ${ }^{72}$ The importance of $\mathrm{Gal}(0)$ in the present context is that very high $\% \mathrm{Gal}(0)$ is seen not only in RA but also in tuberculosis, leprosy (particularly with erythema nodosum leprosum), ${ }^{73}$ and in inflammatory bowel diseases ${ }^{74}$ and a subset of sarcoidosis. ${ }^{75}$ It does not appear to rise in virus infections, or after major surgery, or in a variety of other autoimmune disorders and inflammatory conditions, ${ }^{72}$ including acute rheumatic fever. ${ }^{76}$

How is $\% \mathrm{Gal}(0)$ regulated? There is indirect, but strong evidence that interleukin 6 (IL-6) has a role. Firstly, levels of $\mathrm{Gal}(0)$ were extremely high in transgenic mice overexpressing the human IL-6 gene, ${ }^{77}$ and they rise after direct injection of recombinant IL- 6 into the peritoneal cavities of normal DBA/ 1 mice. ${ }^{78}$ Moreover, levels of IL-6 correlate with $\% \mathrm{Gal}(0)$ in mice injected with pristane, ${ }^{78}$ and in patients with Castleman's disease, or IL-6 secreting tumours (cardiac myxomata and carcinoma of the cervix), ${ }^{79}$ and in the subset of patients with sarcoidosis who have raised $\% \mathrm{Gal}(0)$ (Rook, O'Connor, et al, unpublished observation). These correlations are supported by the observation that IL- 6 causes changes in the activity of galactosyltransferase in B cells, ${ }^{80}$ and it is not surprising to find that the most strikingly raised cytokine in rheumatoid joints is IL-6, which seems to be released spontaneously in vitro by cells derived from such joints. ${ }^{81}$

As IL-6 is a cytokine released nonspecifically in most inflammatory conditions, is it logical to suggest that a raised $\% \mathrm{Gal}(0)$ is 


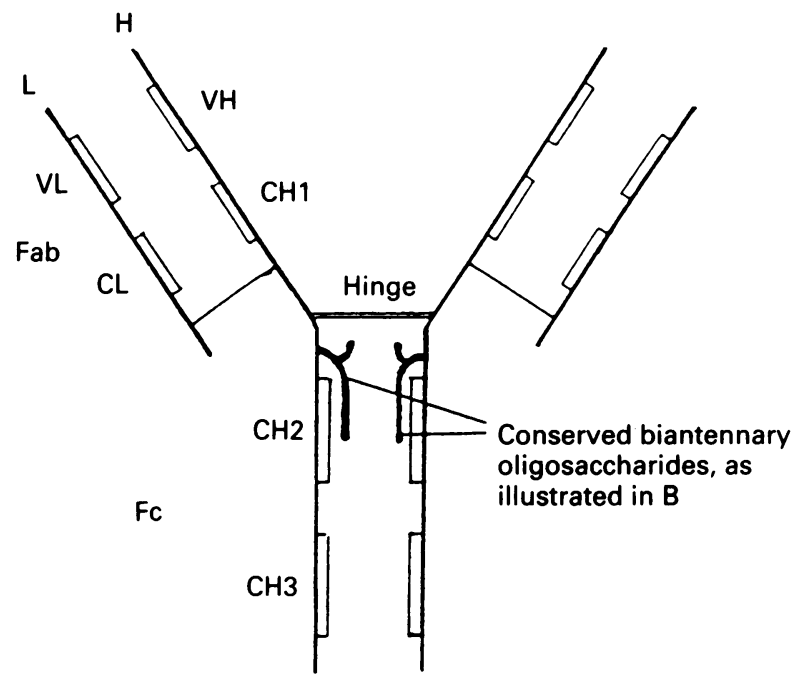

B

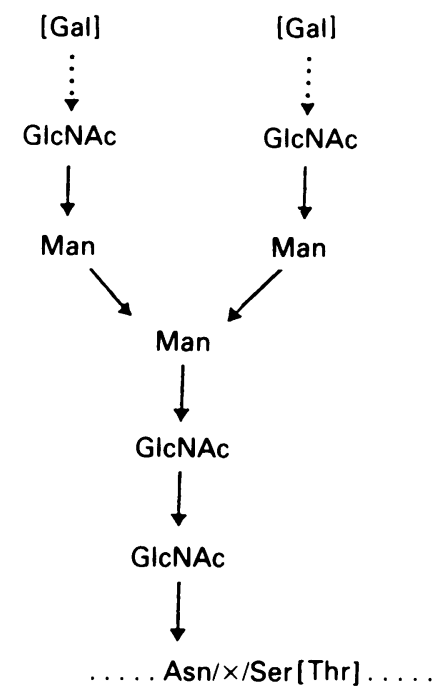

Figure 1 There is a conserved N-glycosylation site at asparagine 297 in the $C H 2$ domain of the IgG heavy chain. This site bears essentially non-sialylated biantennary oligosaccharides, a variable proportion of which bears terminal galactose on one or both of their outer arms. Their location is shown in fig $1 \mathrm{~A}$. When galactose is absent, the terminal sugar is

$N$-acetylglucosamine, as shown in fig $1 B .^{72}$ The proportion of these agalactosyl oligosaccharides is most strikingly increased in tuberculosis, leprosy with erythema nodosum leprosum, rheumatoid arthritis, inflammatory bowel diseases, a subset of sarcoidosis, and Takayasu's arteritis.

evidence for (chronic) infection? At present we cannot answer this question with certainty, but several points lead us to suggest that it is. We emphasise that $\mathrm{Gal}(0)$ levels are markedly higher in the mycobacterioses and in the idiopathic disorders such as RA than in the other inflammatory disorders investigated, and we know that IL-6 is not the only factor involved in its regulation. For instance, striking changes in level are seen during pregnancy, suggesting an endocrinological component. ${ }^{82}$ Moreover, two remarkable recent observations indicate that an unidentified environmental factor can cause a rise in $\% \mathrm{Gal}(0)$ in the absence of overt inflammatory disease. Firstly, it has been noted that $\% \mathrm{Gal}(0)$ rises before onset of RA in Pima Indians. ${ }^{83}$ Secondly, as mentioned earlier, $\% \mathrm{Gal}(0)$ is raised in the spouses of patients with RA. ${ }^{33}$ Only an infection can easily explain these findings.

\section{Does $\mathbf{G a l}(0)$ have a regulatory role?}

Two further strands of circumstantial evidence suggest that $\mathrm{Gal}(0)$ may have a subtle role in the pathogenesis of the disorders in which it is raised. Firstly, babies are usually born with very low levels of $\mathrm{Gal}(0)$ because the level falls dramatically in the maternal circulation during pregnancy, ${ }^{82}$ and because there is selective transport of fully galactosylated forms across the placenta. ${ }^{84}$ In a preliminary study of neonatal lupus erythematosus, congenital heart block was found to occur in those babies who received from their mothers anti-Ro autoantibody together with a high proportion of Gal(0) IgG (Taylor et al, in preparation).

Secondly, the proportion of $\operatorname{Gal}(0)$ rises rapidly post partum, and exacerbation of RA commonly occurs at this time. The serum $\% \operatorname{Gal}(0)$ then overshoots to reach a peak between four and eight months, which corresponds with a peak in autoantibody production. ${ }^{85}$

$\mathrm{We}^{86}$ and others ${ }^{84}$ have suggested elsewhere that $\mathrm{Gal}(0)$ IgG may fail to exert negative feedback on B cells. Normal (galactosylated) IgG does this by cross linking membrane immunoglobulin and $\mathrm{Fc}$ receptors. If $\mathrm{Gal}(0)$ does not have this property, or can block the negative feedback, it may be inappropriate in neonates while the immunological network is being set up, and high levels of it in adults may deregulate autoantibody production. This hypothesis is now being tested.

\section{Animal models}

Superficially the animal models of arthritis do not appear to involve infection as they are evoked without injecting live organisms. Some authors consider these models to be unrelated to the human disorders, but they are accompanied by raised responses to hsp65 and by raised $\% \mathrm{Gal}(0) .{ }^{43} 7782 \mathrm{We}$ regard these areas of overlap with human disease as particularly meaningful. Another striking feature of the rodent models is the influence of unknown environmental factors. This has been observed in MRL mice, in the pristane arthritis model, and in collagen arthritis. In each of these models the incidence of arthritis seems to be influenced by whether the animals are bred under specific pathogen free conditions or not, and by the general cleanliness of the facilities. ${ }^{87}$ It is particularly interesting that $\mathrm{DBA} / 1$ mice from a 'clean' commercial supplier develop little arthritis after intraperitoneal pristane if they are kept in an isolator. The arthritis appears if they are kept outside the isolator in the same area as animals who already have arthritis (Thompson S J, personal communication). Until the nature of the environmental influence in these models is identified, it will 
remain illogical to dismiss the possibility that infection plays a part.

\section{Clues from treatment}

It has recently become apparent that it is the sulphonamide component of sulphasalazine which is the active part of this drug in $\mathrm{RA},{ }^{88}$ and other trials of sulphonamides have been promising. ${ }^{89}$ This effect seems to require sulphonamides which are absorbed, so it is not due only to effects on bowel flora (Bird $\mathrm{H}$, personal communication). There is also evidence that certain tetracyclines can be effective. Some authors believe that the effect of sulphonamide is due to immunosuppression, whereas that of tetracycline is said to be due to inhibition of collagenase, but antimicrobial effects are possible (Bird $\mathrm{H}$, personal communication), and provide less tortuous explanations. The use of rifampicin has yielded variable results. ${ }^{90}$

When RA is treated early with methotrexate, skin nodules may appear. ${ }^{91}$ The histology of these nodules significantly resembles that of the syphilitic gumma, and of early caseous necrosis in tuberculosis. The sudden appearance of new skin lesions is not uncommon in leprosy when there is an acute increase in immunological recognition of bacteria in the skin. In a murine model of anergy induced by overloading mice with a large dose of intravenous mycobacteria, methotrexate was found to restore delayed hypersensitivity to the bacterial antigens. ${ }^{92}$ This point is important, because we consider freshly developing nodules to be the sites in which organisms are most likely to be demonstrable in RA.

\section{Existence of appropriate forms of mycobacteria and of related genera}

The genus Nocardia, closely related to the mycobacteria, can cause unexpected disease, and can do so in a form with defective cell walls. Thus Nocardia caviae can switch to a pathogenic form with defective cell walls after intranasal administration to mice. This form is associated with extensive lung damage at a time when normal forms of the nocardiae can neither be seen nor isolated. ${ }^{93}$ Even more remarkable is the recent observation that small intravenous inocula of this organism adhere to endothelial cells in the vasculature of the brain, pass through the endothelium, and then become undetectable by conventional means. However, at this time the mice develop an L-DOPA responsive movement disorder, similar to parkinsonism. ${ }^{94}$

There have been sporadic reports of mycobacterial forms with defective cell walls which would not be detected in tissues by the usual Ziehl-Neelsen technique. Several groups have isolated such organisms from patients with inflammatory bowel disease, ${ }^{95-97}$ sarcoidosis, ${ }^{98}$ and tuberculosis. ${ }^{99-101}$ Initial cultures from lymph node draining lesions of Crohn's disease take nine to 24 months to produce appreciable growth, though on subculture this falls to a minimum of three months. Traces of tuberculostearic acid and of mycolic acids, together with a degree of DNA homology demonstrated on dot blots, firmly associate these organisms with mycobacteria or with other genera clustered at the mycobacterial end of the corynebacterium-mycobacterium axis. ${ }^{97}$ Electron microscope studies have shown that although pleomorphic they are not spheroplasts in the true sense, though they may lack the arabinogalactan layer of the conventional mycobacterial wall. Conceivably they are the equivalent of the 'filter-passing' Much's granular form of tubercle bacilli described in $1907 .{ }^{99}$ Recently it has proved possible to passage these organisms from inflammatory bowel diseases in $\mathrm{Nu} / \mathrm{Nu}$ mice, in which they have reverted to bacillary forms. By restriction fragment length polymorphism analysis these appear to be unusual organisms, not $M$ paratuberculosis. Moreover, part of the gene encoding the $16 \mathrm{~S}$ ribosomal RNA has been sequenced, and indicates a novel slow growing mycobacterium (McDermott, Moss, Stanford, et al, in preparation). The organisms grown from cases of sarcoidosis were morphologically similar, ${ }^{98}$ and their existence is supported by the demonstration of mycobacterial DNA in alveolar lavage material ${ }^{102}$ and splenic tissue from this disease. ${ }^{103}$ Such forms of mycobacterium may correspond to the 'stationary phase', which is now well recognised in other genera. ${ }^{104}$ Stationary phase organisms are roughly spherical, reduced in size, and have grossly altered cell walls and metabolism. They may lose the ability to transport substrates into the cell, rendering them difficult or impossible to recover by culture. There are several particularly relevant properties of stationary organisms. Firstly, they tend to increase their levels of hsps and of superantigens. Evidence for the involvement of hsps in RA was discussed earlier, and recent studies have detected changes in usage of $V \beta$ in $T$ cell receptors which may imply past or continuing influence of superantigens in this disease. ${ }^{105}$ Secondly, the very small forms with altered cell walls may not be detectable by periodic acidSchiff reagent or Ziehl-Neelsen stains (used for Whipple's disease and mycobacteria respectively), so the infections can easily go undetected.

\section{Concluding remarks}

We have reviewed some evidence in support of the hypothesis that RA and several other 'idiopathic' or 'autoimmune' diseases are the result of infection by slow growing microorganisms similar to mycobacteria. The main arguments are: (1) The shared features of the diseases caused by slow growing organisms (for example, mycobacteria, spirochaetes, etc) and RA. These include arthritis, autoantibodies, rheumatoid factor, and strikingly raised $\mathrm{Gal}(0) .{ }^{86}$ (2) The importance of non-genetic environmental factors in RA, shown by studies of twins. ${ }^{30}$ (3) Serological changes found in the spouses of patients with RA. ${ }^{33}$ (4) Absence of 


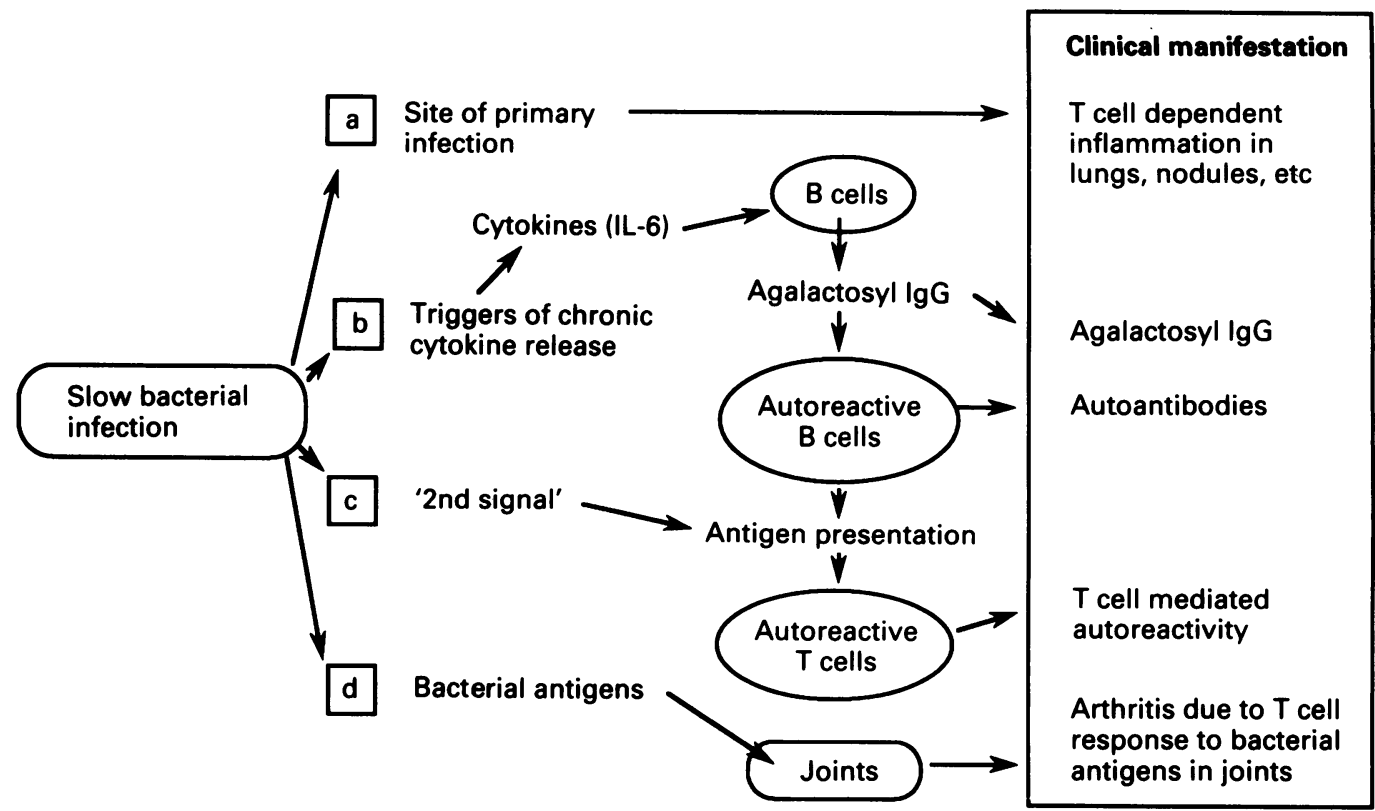

Figure 2 Four properties of slow bacterial infection which may lead to disease resembling autoimmunity. (a) Variable $T$ cell dependent inflammation in the primary site of infection, mostly in the skin, lungs, or gut. As exemplified in the disease spectrum of leprosy, the characteristics of this response will depend on the balance between the $T$ cell mediated and antibody components. (b) Chronic cytokine release leading to increased agalactosyl IgG. ${ }^{77} 79$ This in turm may deregulate autoreactive $B$ cells, ${ }^{84} 86$ which then produce autoantibodies and also act as efficient presenters of antigen to autoreactive $T$ cells. $(c)$ The efficiency of this $T$ cell activation may be enhanced by the 'second signal' triggered by bacterial products present in the joint. . $3-2655^{23}$ (d) The arthritis, when it occurs, may be due mostly to T cells responding to bacterial antigens sequestrated in the joint, ${ }^{23-26}$ though autoreactive $T$ cells and autoantibodies may contribute. ${ }^{38-41}$ (Reproduced, with permission, from reference 86. .)

good evidence for relevant autoreactive $T$ cells in RA. (5) Altered antibody and skin test responses to mycobacteria in $\mathrm{RA}$. The skin test changes correlate with DR4 in $\mathrm{RA}^{59}$ and leprosy $^{60}$ but not in normal subjects. (6) Responses to the mycobacterial 65 kilodalton hsp in most, perhaps all, the rodent models of arthritis, together with evidence that environmental microorganisms also have a crucial role in these models.

Figure 2 illustrates these and other arguments combined in the hypothesis. The arrival of recombinant DNA technology means that the role of infections in RA, inflammatory bowel diseases, and sarcoidosis will be established or refuted within the next few years. If the infection hypothesis proves to be correct the treatment of RA will need to be completely revised, and the consequences for the pharmaceutical industry will be enormous. It could become unethical to use steroids, or agents which block prostaglandin synthesis, as we cannot be sure that they do not promote proliferation of the organism, and so in the long term lead to more severe disease. Instead we will need to devise antibiotic regimens and immunotherapeutic protocols.

We would like to thank Dr J McCulloch for his critical reading of the manuscript.

1 McClure H M, Chiodini R J, Anderson D C, Swenson R B, Thayer W R, Coutu J A. Mycobacterium paratuberculosis infection in a colony of stumptail macaques.

2 Connolly G M, Shanson D, Hawkins D A, Webster J N, Gazzard B G. Non-cryptosporidial diarrhoea in human immunodeficiency virus (HIV) infected patients. Gut 1989; 30: 195-200.

3 Chiodini R J. Crohn's disease and the mycobacterioses: a review and comparison of two disease entities. Clin Microbiol Rev 1989; 2: 90-117.
4 Smiejan J M, Cosnes J, Chollet-Martin S, et al. Sarcoidlike lymphocytosis of the lower respiratory tract in patients with active Crohn's disease. Ann Intern Med 1986; 104: 17-21.

5 Gilligan D M, O'Connor C M, Ward $\mathrm{K}$, et al. Bronchoalveolar lavage in patients with mild and severe rheumatoid lung disease. Thorax 1990; 45: 591-6.

6 McCormick P A, Feighery C, Dolan C, et al. Altered gastrointestinal immune response in sarcoidosis. Gut 1988; 29: 1628-31.

7 Doube A, Collins A J. Is the gut intrinsically abnormal in rheumatoid arthritis? Ann Rheum Dis 1988; 47: 617-9.

8 Sahn E E, Hampton M T, Garen P D, Warrick J, Smith D, Silver R M. Preschool sarcoidosis masquerading as juvenile rheumatoid arthritis: two case reports and a review of the literature. Pediatr Dermatol 1990; 7 208-13.

9 Gravallese E M, Kantrowitz F G. Arthritic manifestations of inflammatory bowel disease. Am $\mathcal{F}$ Gastroenterol 1988 83: 703-9.

10 Spapen H D, Segers O, De-Wit N, et al. Flectron microscopic detection of Whipple's bacillus in sarcoidlike periodic acid Schiff-negative granulomas. Dig Dis $\mathrm{Sc}$ 1989; 34: 640-3.

11 Vanderschueren D, Dequeker J, Geboes K. Whipple's disease in a patient with longstanding seronegative disease in a patient with longstanding serone
polyarthritis. Scand f Rheumatol 1988; 17: 423-6.

12 Wilson K H, Blitchington R, Frothingham R, Wilson J A $P$. Phylogeny of the Whipple's-disease-associated bacterium. Lancet 1991; 338: 474-5.

13 Ramu G, Balakrishnan S. Arthritis in lepromatous leprosy. Leprosy in India 1968; 40: 1-8.

14 Atkin S L, Welbury R R, Stanfield E, Beavis D, Iwais B, Dick W C. Clinical and laboratory studies of inflammatory polyarthritis in patients with leprosy in Papua New Guinea. Ann Rheum Dis 1987; 46: 688-90.

15 Isaacs A J, Sturrock R D. Poncet's disease - fact or fiction? A reappraisal of tuberculous rheumatism. Tubercle 1974; 55: $135-42$.

16 Ames P R J, Capasso G, Testa V, Mafulli X, Tortova M Gaeta G B. Chronic tuberculous rheumatism (Poncet's Gaeta G B. Chronic tuberculous rheumatism (Poncet's

17 Askari A, Kyi T, Patel J M, Chopra M P. Acute arthropathy in mediastinal tuberculosis. Respir Med 1992; 86: 57-9.

18 Dall L, Long L, Stanford J. Poncet's disease: tuberculous rheumatism. Rev Infect Dis 1989; 11: 105-7.

19 Southwood T R, Hancock E J, Petty R E, Malleson P N, Thiessen $\mathbf{P}$ N. Tuberculous rheumatism (Poncet's disease) in a child. Arthritis Rheum 1988; 31: 1311-3.

20 Maricic M J, Alepa P P. Reactive arthritis afte Mycobacterium avium-intracellulare infection: Poncet's disease revisited. Am $\mathcal{Y}$ Med 1990; 88: 549-50.

21 Hughes R A, Allard S A, Maini R N. Arthritis associated with adjuvant mycobacterial treatment for carcinoma of the bladder. Ann Rheum Dis 1989; 48: 432-4.

22 Torisu M, Miyahara T, Shinohara N, Ohsato K, Sonozak H. A new side-effect of BCG immunotherapy; BCGinduced arthritis in man. Cancer Immunol Immunother 1978; 5: 77-83. 
23 Gaston J S H, Life P, Granfors K, et al. Synovial T lymphocyte recognition of organisms which trigger reactive arthritis. Clin Exp Immunol 1989; 76: 348-53.

24 Granfors K Jalkanen S, Lindberg A A, et al. Salmonell lipopolysaccharide in synovial cells from patients with reactive arthritis. Lancet 1990; 335: 685-8.

25 Wordsworth B P, Hughes R A, Allan I, Keat A C, Bell J I. Chlamydial DNA is absent from the joints of patients with sexually acquired reactive arthritis. $\mathrm{Br} \mathcal{F}$ Rheumatol 1990; 29: 208-10

26 Viitanen A M, Arstila T P, Lahesmaa R, Granfors K, Skurnik M, Toivanen P. Application of the polymerase chain reaction and immunofluorescence techniques to the detection of bacteria in yersinia-triggered reactive arthritis. Arthritis Rheum 1991; 34: 89-96.

27 Hills S E, Parkes S A, Baker S B. Epidemiology of sarcoidosis in the Isle of Man-2: Evidence for space-time clustering. Thorax 1987; 42: 427-30.

28 Ekbom A, Helmick C, Zack $M$, Adami $\mathrm{H}$ O. The epidemiology of inflammatory bowel disease: a large, population-based study in Sweden. Gastroenterology 1991; 100: 350-8.

29 Sonnenberg A, McCarty D J, Jacobsen S J. Geographic variation of inflammatory bowel disease within the United States. Gastroenterology 1991; 100: 143-9.

30 Silman A J. Is rheumatoid arthritis an infectious disease? BMF 1991; 303: 200-1.

31 Shoenfeld Y, Isenberg D A. Mycobacteria and autoimmunity. Immunol Today 1988; 9: 178-82.

32 Korsmeyer S J, Williams R C, Wilson I D, Strickland R G. Lymphocytotoxic antibody in inflammatory bowel
disease. A family study. $N$ Engl 7 Med 1975; 293: disease. A

33 Sumar N, Colaco C B, Bodman K B, et al. Abnormalities in the glycosylation of IgG in spouses of patients with rheumatoid arthritis. A family study. F Autoimmun 1991; 4: 907-14.

34 Youinou P, Williams W, Le-Goff P, et al. Serological abnormalities, including common idiotype PR4, in families with rheumatoid arthritis. Ann Rheum Dis 1989; 48: 898-904.

35 Colaco C B, Harris G, Lawley P D, Lydyard P M, Roitt I $M$. Deficient repair of $0^{6}$-methylguanine in lymphocytes from rheumatoid arthritis families may be an acquired defect. Clin Exp Immunol 1988; 72: 15-19.

36 Foldes C, Vauthieu J, Bentata M, Perie G. Sacoidose conjugale. Ann Dermatol Venereol 1991; 118: 834-6.

37 de Vries R R. Genetic control of immunopathology induced by Mycobacterium leprae. Am $\mathcal{F}$ Trop Med Hyg 1991; 44: 12-16.

38 Londei M, Savill C M, Verhoef A, et al. Persistence of collagen type II-specific T-cell clones in the synovial membrane of a patient with rheumatoid arthritis. Proc Natl Acad Sci USA 1989; 86: 636-40.

39 Elkayam O, Zinger H, Zisman E, et al. Regulatory T cell activity specific to human type II and III collagens in rheumatoid arthritis. F Rheumatol 1991; 18: 516-21.

40 Lacour M, Rudolphi U, Schlesier M, Peter H H. Type II collagen-specific $\mathrm{T}$ cells in healthy donors. Eur $\mathcal{F}$ Immunol 1991; 21: 1092 .

41 van Eden W. Heat-shock proteins as immunogenic bacterial antigens with the potential to induce and regulate autoimmune arthritis. Immunol Rev 1991; 121: $5-28$.

42 van den Broek $M F$, van Bruggen $M C J$, Hogervorst $E$ J $M$, van Eden W, van der Zee R, van den Berg W B. Protection against streptococcal cell wall-induced arthritis by pretreatment with the mycobacterial $65 \mathrm{kDa}$ heat shock protein. $\mathcal{F}$ Exp Med 1989; 170: 449-66.

13 Thompson S J, Rook G A W, Brealey R, van der Zee R, Elson C J. Autoimmune reactions to heat shock proteins in pristane-induced arthritis. Eur F Immunol 1990; 20: 2479-84.

44 Billingham M E J, Carney S, Butler R, Colston M J. A mycobacterial $65 \mathrm{kDa}$ heat shock protein induces antigen-specific suppression of adjuvant arthritis, but is not itself arthritogenic. $\mathcal{F}$ Exp Med 1990; 171: 339-44.

45 de Graeff-Meeder E R, van der Zee R, Rijkers G T, et al. Recognition of human $60 \mathrm{kD}$ heat shock protein by mononuclear cells from patients with juvenile chronic arthritis. Lancet 1991; 337: 1368-72.

46 Gaston J S, Life P F, van der Zee R, et al. Epitope specificity and MHC restriction of rheumatoid arthritis synovial $\mathrm{T}$ cell clones which recognize a mycobacterial $65 \mathrm{kDa}$ heat shock protein. International Immunology 1991; 3: 965-72.

47 Smilek D E, Wraith D C, Hodgkinson S, et al. A single amino acid change in a myelin basic protein peptide confers the capacity to prevent rather than induce experimental autoimmune encephalomyelitis. Proc Nat Acad Sci USA 1991; 88: 9633-7.

48 Koga $T$, Wand-Wurttenberger A, DeBruyn J, Munk M E, Schoel B, Kaufmann $S$ H. T cells against a bacterial heat shock protein recognise stressed macrophages. Science 1989; 245: 1112-5.

49 Steinhoff U, Schoel B, Kaufmann S H. Lysis of interferon gamma-activated Schwann cells by cross-reactive CD8+ alpha/beta $T$ cells with specificity for the mycobacterial $65 \mathrm{kDa}$ heat shock protein. International Immunology 1990; 2: 279-84.

50 Hermann E, Lohse A W, van der Zee R, et al. Synovia fluid-derived yersinia-reactive $T$ cells responding to human $65-\mathrm{kDa}$ heat shock protein and heat-stressed antigen-presenting cells. Eur f Immunol 1991; 21: antigen-prest
51 Li S G, Quayle A J, Shen Y, et al. Mycobacteria and human heat-shock protein-specific cytotoxic $T$ lymphocytes in rheumatoid synovial inflammation. Arthritis Rheum 1992; 35: 270-81.

52 Wand-Wurttenburger A, Schoel B, Ivanyi J, Kaufmann S $\mathrm{H}$. Surface expression by mononuclear phagocytes of an epitope shared with mycobacterial heat shock protein 60 . Eur f Immunol 1991; 21: 1089-92.

53 Jarjour W, Mizzen L A, Welch W J, et al. Constitutive expression of a groEL-related protein on the surface of human gamma/delta cells. $\mathcal{f}$ Exp Med 1990; 172 1857-60.

54 Fisch P, Malkovsky M, Kovats S, et al. Recognition by human V gamma 9/V delta $2 \mathrm{~T}$ cells of a GroEL homolog on Daudi Burkitt's lymphoma cells. Science 1990; 250 1269-73.

55 Janeway C A. Immunogenicity signals $1,2,3 \ldots$ and 0 (news). Immunol Today 1989; 10: 283-6.

56 Rook G A W. Mobilising the appropriate T cell subset: the immune response as taxonomist. Tubercle 1991; 72: 253-4.

57 Tsoulfa G, Rook G A W, van Embden J D A, et al. Raised serum IgG and IgA antibodies to mycobacterial antigen in rheumatoid arthritis. Ann Rheum Dis 1989; 48 $118-23$

58 Bahr G M, Rook G A W, Al-Saffar M, van Embden J, Stanford J L, Behbehani K. Antibody levels to mycobacteria in relation to HLA type: evidence for nonHLA-linked high levels of antibody to the $65 \mathrm{kDa}$ heat shock protein of $M$. tuberculosis in rheumatoid arthritis. Clin Exp Immunol 1988; 74: 211-5.

59 Bahr G M, Sattar M A, Stanford J L, et al. HLA-DR and tuberculin tests in rheumatoid arthritis and tuberculosis. tuberculin tests in rheumatoid a
Ann Rheum Dis $1989 ; 48: 63-8$.

60 Ottenhoff T H, Torres P, de las Aguas J T, et al. Evidence for an HLA-DR4-associated immune-response gene fo Mycobacterium tuberculosis. A clue to the pathogenesis of rheumatoid arthritis. Lancet 1986; ii: 310-3.

61 Palacios-Boix A A, Estrada G I, Colston M J, Panayi G S. HLA-DR4 restricted lymphocyte proliferation to a Mycobacterium tuberculosis extract in rheumatoid arthritis and healthy subjects. $\mathcal{f}$ Immunol 1988; 140: $1844-50$.

62 McLean I L, Archer J R, Cawley M I, et al. Specific antibody response to the mycobacterial $65 \mathrm{kDa}$ stress
protein in ankylosing spondylitis and rheumatoid protein in ankylosing spondylitis and
arthritis. Br $\mathcal{f}$ Rheumatol 1990; 29: 426-9.

63 Tsoulfa G, Rook G A W, Bahr G, et al. Elevated IgG antibody levels to the mycobacterial $65 \mathrm{kDa}$ heat shock protein are a characteristic of patients with rheumatoid arthritis. Scand f Immunol 1988; 30: 519-27.

64 Rambukkana A, Das P K, Witkamp L, Yong S, Meinardi $\mathrm{M}$, Bos J D. Antibodies to mycobacterial $65 \mathrm{kDa}$ heat shock protein and other immunodominant antigens in patients with psoriasis. F Invest Dermatol. In press.

65 Res P C, Schaar C G, Breedveld F C, et al. Synovial fluid $T$ cell reactivity against $65 \mathrm{kD}$ heat shock protein of mycobacteria in early chronic arthritis. Lancet 1988; ii 478-80

66 Pope R M, Lovis R M, Gupta R S. Activation of synovial fluid $\mathrm{T}$ lymphocytes by $60 \mathrm{kDa}$ heat shock proteins in patients with inflammatory synovitis. Arthritis Rheur 1992; 35: 43-8.

67 Fischer H P, Sharrock C E, Colston M J, Panayi G S. Limiting dilution analysis of proliferative $T$ cell responses to mycobacterial $65-\mathrm{kDa}$ heat-shock protein fails to show significant frequency differences between synovial fluid and peripheral blood of patients with rynoumatoid arthritis. Eur f Immunol 1991; 21: 2937-41.

68 Sioud M, Kjeldsen-Kragh J, Quayle A J, et al. Immune responses to 18.6 and $30 \mathrm{kDa}$ mycobacterial antigens in
rheumatoid arthritis patients, and $\mathrm{V} \beta$ usage by specific rheumatoid arthritis patients, and V $\beta$ usage by specific
synovial T cell lines and fresh T cells. Scand $\mathcal{f}$ Immuno synovial $T$ cell lines

69 Res P C, Orsini D I, Van-Laar J M, Janson A A, AbouZeid C, de Vries R R. Diversity in antigen recognition by Mycobacterium tuberculosis- reactive $T$ cell clones from the synovial fluid of rheumatoid arthritis patients. Eur f Immunol 1991; 21: 1297-302.

70 Pope R M, Wallis R S, Sailer D, Buchanan T M, Pahlavan $\mathrm{M}$ A. T cell activation by mycobacterial antigens in inflammatory synovitis. Cell Immunol 1991; 133: inflammator.

71 Ask-Upmark E. On the pulseless disease outside Japan Acta Med Scand 1954; 149: 161-78.

72 Rademacher T, Parekh R B, Dwek R A, et al. The role of IgG glycoforms in the pathogenesis of rheumatoid arthritis. Springer Semin Immunopathol 1988; 10 231-49.

73 Filley E, Andreoli A, Steele J, et al. A transient rise in agalactosyl IgG correlating with free IL-2 receptors during episodes of erythema nodosum leprosum. Clin Exp Immunol 1989; 76: 343-7.

74 Dube R, Rook G A, Steele J, et al. Agalactosyl IgG in inflammatory bowel disease: correlation with C-reactive inflammatory bowel disease:

75 O'Connor C M, Rook G A W, Fitzgerald M X. In: James G, Izumi T, eds. Proceedings of the world conference on $\mathrm{G}$, Izumi $\mathrm{T}$, eds. Proceedings of the world conference
sarcoidosis and other granulomatous diseases. In press.

76 Bahr G M, Yousof A M, Majeed H A M, et al. Agalactosyl IgG, antibodies to heat shock proteins, and acute rheumatic fever. Ann Rheum Dis 1990; 49: 383-6.

77 Rook G A W, Thompson S, Buckley M, et al. The role of oil and agalactosyl IgG in the induction of arthritis in rodent models. Eur f Immunol 1991; 21: 1027-32. 
78 Hitsumoto Y, Thompson S J, Zhang Y, Rook G A W, Elson C J. Relationship between interleukin 6, agalactosyl IgG and pristane-induced arthritis. augalactosyl IgG and pristanity 1992; 11: 247-54

79 Nakao H, Nishikawa A, Nishiura T, Kanayama Y, Tarui S, Taniguchi N. Hypogalactosylation of immunoglobulin G sugar chains and elevated serum immunoglobulin G sugar chains and elevated serum 1991; 197: 221-8.

80 Nakao H, Nishikawa A, Karasuno T, et al. Modulation of $\mathrm{N}$-acetylglucosaminyltransferase III, IV and V activities and alteration of the surface oligosaccharide structure of a myeloma cell line by interleukin 6. Biochem Biophys Res Commun 1990; 172: 1260-6.

81 Hirano $T$, Matsuda $T$, Turner $M$, et al. Excessive production of interleukin $6 / \mathrm{B}$ cell stimulatory factor-2 in proumatoid arthritis. Eur $\mathcal{f}$ Immunol 1988; 18: rheumatoid

82 Rook G A W, Steele J, Brealey R, et al. Changes in IgG glycoform levels are associated with remission of arthritis during pregnancy. $\mathcal{F}$ Autoimmun 1991; 4: 779-94.

83 Schrohenholer R E, Tomana M, Koopman W J, Del Puente A, Bennet P H. Occurrence of IgG galactosylation deficiency prior to the onset of rheumatoid arthritis [Abstract]. Arthritis Rheum 1991; 34: R28.

84 Rademacher T W. Network theory of glycosylation aetiologic and pathogenic implication of changes in IgG glycoform levels in autoimmunity. Seminars in Cell glycoform levels in au
Biology 1992; 2: 327-37.

85 Amino N, Kuro R, Tanizawa O, et al. Changes of serum anti-thyroid antibodies during and after pregnancy in
autoimmune thyroid diseases. Clin Exp Immunol 1978; 31: 30-7.

86 Rook G A W, Stanford J L. Slow bacterial infections or autoimmunity. Immunol Today 1992; 13: 160-4.

87 Isenberg D A, Katz D, Le Page S, et al. Independent analysis of the $16 / 6$ idiotype lupus model. A role for an environmental factor. $\mathcal{F}$ Immunol 1991; 147: 4172-7.

88 Pullar T, Hunter J A, Capell H A. Which component of sulph 1985; 290: 1535-8.

89 Kalliomaki J L. A therapeutic trial with a combination of trimethoprim-sulphamethoxazole in rheumatoid arthritis Current Therapeutic Research 1972; 14: 22-5.

90 Cox N L, Prowse M V, Maddison M C, Maddison P J. Treatment of early rheumatoid arthritis with rifampicin. Ann Rheum Dis 1992; 51: 32-4.

91 Segal R, Caspi D, Tishler M, Fishel B, Yaron $M$ Accelerated nodulosis and vaculitis during methotrexate therapy for rheumatoid arthritis. Arthritis Rheum 1988; 31: 1182-5.

92 Kato K, Yamamoto K. Restoration of suppressed delayed type hypersensitivity induced in mice by live BCG after methotrexate administration. Int $\mathcal{f}$ Immunopharmacol methotrexate admi

93 Beaman B L. Induction of L-phase variants of Nocardia caviae within intact murine lungs. Infect Immun 1980; 29: 244-51

94 Kohbata S, Beaman B L. L-dopa-responsive movement disorder caused by Nocardia asteroides localized in the brains of mice. Infect Immun 1991; 59: 181-91.

95 Burnham W R, Lennard-Jones J E, Stanford J L, Bird R G. Mycobacteria as a possible cause of inflammatory bowel disease. Lancet 1978; ii: 693-6.

96 Chiodini R J, Van-Kruiningen H J, Thayer W R, Coutu J A. Spheroplastic phase of mycobacteria isolated from patients with Crohn's disease. $\mathcal{F}$ Clin Microbiol 1986; 24: patients

97 Visuvanathan S. The characterisation of pleomorphic acidfast organisms isolated from patients with inflammatory bowel disease. University of London, 1990. (MD thesis.)

98 Graham D Y, Markesich D C, Kalter D C, Yoshimura H $\mathrm{H}$. Isolation of cell-wall-defective acid-fast bacteria from skin lesions of patients with sarcoidosis. In: Grassi C, Rizzato G, Pozzi E, eds. Sarcoidosis and other granulomatous disorders. Amsterdam: Elsevier, 1988: 161-3.

99 Much H. Uber die granulare, nach Ziehl nicht darstellbare Form des Tuberkulosevirus. Beitrage zur Klinischen Form des Tuberkulosevi

100 Chandrasekhar S. Cell wall deficient forms of tubercle bacilli. Indian f Chest Dis 1978; 22: 114-22.

101 Khomenko A G. The variability of Mycobacterium tuberculosis in patients with cavitatory pulmonary tuberculosis in the course of chemotherapy. Tubercle 1987; 68: 243-53.

102 Saboor S, Johnson N M, McFadden J. Use of the polymerase chain reaction to detect mycobacterial DNA in tuberculosis and sarcoidosis. Lancet 1992; 339: 1012-5.

103 Mitchell I C Turk J I Mitchell D N. Detection of mycobacterial rRNA in sarcoidosis with liquid phase mycobacterial rRNA in sarcoidosis with

104 Siegele D A, Kolter R. Life after log. F Bacteriol 1992; 174: 345-8.

105 Paliard X, West S G, Lafferty J A, et al. Evidence for the effects of a superantigen in rheumatoid arthritis. Science 1991; 253: 325-9. 